\title{
CHART MYTHOS
}

\section{The JAMs' and The KLF's Invocation of $\mathrm{Mu}$}

[Received August $18^{\text {th }} 2016$; accepted September $22^{\text {nd }} 2016$ - DOI: 10.21463/shima.10.2.07]

\section{Jon Fitzgerald}

<jonwfitzgerald@gmail.com> Southern Cross University

\section{Philip Hayward}

<prhshima@gmail.com> Kagoshima University Research Center for the Pacific Islands and University of Technology Sydney

\begin{abstract}
The JAMs and The KLF, two overlapping popular music ensembles led by British multi-media performers Jimmy Cauty and Bill Drummond, were notable for both the success they had with a batch of singles in the late 1980 os and early 1990 and the complex mythology they constructed and celebrated in song lyrics, music videos, press releases and short films. Key to their mythological project was their association with the fictional lost island-continent of $\mathrm{Mu}$ (with the band name JAMs being an abbreviation for 'Justified Ancients of $\mathrm{Mu} \mathrm{Mu').} \mathrm{The} \mathrm{latter} \mathrm{identity} \mathrm{was} \mathrm{derived} \mathrm{from} \mathrm{Robert} \mathrm{Shea} \mathrm{and} \mathrm{Robert} \mathrm{Anton}$ Wilson's Illuminatus trilogy of novels in which the aforementioned "ancients" were a secret brotherhood involved in combatting the rival Illuminati, who originated in Atlantis. As the JAMS' and KLF's oeuvres progressed, aspects of Mu and Atlantis were synthesised by Cauty and Drummond with elements of other actual and fictional islands. The article traces the initial imagination and representation of $\mathrm{Mu}$ in esoteric crypto-historical literature, its rearticulation in Shea and Wilson's counter-cultural novels and its invocation and function in Cauty and Drummond's work with The JAMs and The KLF.
\end{abstract}

KEY WORDS: Mu, Atlantis, Illuminatus trilogy, The JAMs, The KLF

\section{Introduction}

Over a five-year period, the British duo of Jimmy Cauty and Bill Drummond produced a series of invocations and, eventually, audiovisual realisations of the fictional lost island of $\mathrm{Mu}$ through their work with two ensembles: The Justified Ancients of $\mathrm{Mu} \mathrm{Mu}^{1}$ (commonly referred to as The JAMs) and The KLF. ${ }^{2}$ This article tracks the lineage of the concept of Mu that informed Cauty and Drummond's work, examines its cryptic invocation in the duo's early recordings, media statements and media materials and then turns to analyse its representations in music videos and a film produced by KLF Communications in the early 1990s. In examining the function of $\mathrm{Mu}$, the related mythical island of Atlantis and those of

\footnotetext{
${ }^{1}$ This spelling differs from Shea and Wilson's original references to "Mummu" due to what was an error on the duo's part rather than an attempt to distinguish their band project from the referent novels (Higgs, 2012: 95).

${ }^{2}$ The initials KLF are generally accepted as standing for Kopyright Liberation Front (although the ensemble was never referred to as such).
} 
other actual and fictional islands, the article details the manner which the duo's work created an inscription of $\mathrm{Mu}$ (cross-fertilised with other locations) that represents a continuing tradition of representing islands as mystic 'elsewheres' across a range of cultural media. In the sections that follow, particular attention is given to both the duo's cultural careers and the particular nature of their operation as artists strongly influenced by countercultural rhetoric at the same time as they worked within the commercial music industry, being variously enabled and constrained by its institutions, practices and audiences.

\section{The Roots of The JAMs}

The two British multimedia artists who performed as The JAMs ${ }^{3}$, The KLF (and, briefly, as The Timelords ${ }^{4}$ ) in the late 1980 os-early 1990 s came into the music industry via different routes. Cauty was a high school dropout and amateur artist who achieved success with a painting of Gandalf, the wizard from Tolkien's fantasy novels The Hobbit and The Lord of the Rings, when it became one of the most successful posters ever produced by the British Athena company. The painting represented Gandalf, a member of the mystical Istari order and leader of the Fellowship of the Rings, as standing wise and resilient in a highly stylised mountainous landscape. Despite painting a number of similar works that explored a particularly British style of bucolic fantasy (including the cover of folk musicians Bob Johnson and Peter Knight's King of Elfland's Daughter album [1977]), Cauty shifted into rock music in the late 1970s, performing as a guitarist with the post-punk group Angels 1-5 before joining major label bands Brilliant (1982-86) and Zodiac Mindwarp and the Love Reaction (1986-88) and going on to found the ambient-electronica ensemble The Orb with Alex Paterson in 1988.

Drummond attended art school in the early-mid 1970s before commencing work with Ken Campbell's Science Fiction Theatre of Liverpool (SFTL) company and working on a variety of other jobs before entering the music business in 1977 as a member of indie band Big in Japan. He then founded the Zoo Records label in 1978, went on to produce and manage the bands Echo and The Bunnymen and Teardrop Explodes, in a somewhat idiosyncratic manner, ${ }^{5}$ and embarked on a short-lived career as a singer-songwriter ${ }^{6}$ before teaming up with Cauty in 1988. One aspect of Drummond's early career that proved particularly influential was his design of stage sets for SFTL's production of a 12 hour long adaptation of Robert Shea and Robert Anton Wilson's Illuminatus trilogy of novels in Liverpool in 1976. His designs and constructions involved considerable low-budget ingenuity and he has subsequently stressed the influence that Campbell's iconoclastic approach had on his later

\footnotetext{
${ }^{3}$ The capitalisation and number of letters in the band's initialised acronym vary in both the ensemble's usage and in press articles and fan Internet sites where they are also referred to as The JAMS or JAMMS.

${ }^{4}$ An identity adopted for the production of their single and music video for Doctorin' the Tardis, an homage to BBC Television's long running Sci-Fi series Dr. Who, in 1988 (see Fitzgerald and Hayward, 2013).

${ }^{5}$ Including organising a tour for Echo and the Bunnymen based around ancient British ley line routes and involving several gigs in the western Scottish isles of Lewis and Skye (see Gilbert, 2016: 30).

${ }^{6}$ With the release of his 1986 album The Man (Creation Records).
} 
work (Drummond, 2014). Shea and Wilson's novels ${ }^{7}$ combined SF and fantasy themes in a complex narrative format that referred to two secret cults locked in combat - the Illuminati, bent on world domination, and the Justified Ancients of Mummu, who were 'Discordians' devoted to chaos and subversion. Abstracting a summary characterisation out of a complex and often cryptically obscure narrative, Mummu was both a period of primordial chaos and an individual killed in conflicts between the Gods in this period. The Justified Ancients of Mummu were an anarchistic group that emerged to claim that Mummu was still alive - a contention supposedly supported by the prevalence of chaos in the world. The Justified Ancients later became reconciled with their arch enemies the Illuminati until they were expelled in the 1880 os (with the MC5's [actual] 1969 single 'Kick out the Jams' being represented as a taunting reminder of that incident). ${ }^{8}$ In the novels, the Justified Ancients were deeply opposed to the conservative contemporary music industry and were involved in subverting it.

Cauty and Drummond's use of this loose mythology in their mid-1980s to early 1990s output also evokes and draws on a body of fanciful literary works that Shea and Wilson derived their own cosmology from. The works in question postulated the existence of (and suggested a variety of locations and characterisations for) a lost island continent named $\mathrm{Mu}$. Jordan (2001: 50-62) provides a succinct overview of the development of the myth. Mu first emerged as an alternative name for Atlantis (or, at least, for Atlantis imagined as a lost island civilisation located in the north Atlantic) in publications by Le Plongeon that drew on (highly flawed) early studies of central American Mayan culture made by French historian Brasseur de Boubourg in the mid-late 1800 . Le Plongeon proposed that $\mathrm{Mu}$ was a continental island that hosted a civilisation that was associated with the Mayans and that facilitated the development of early Egyptian civilisation (see Lawrence and Messenger, 1998). In Le Plongeon's account, Mu was destroyed by a cataclysm that resulted in its submergence. Woven into this schema was a story concerning a princess from $\mathrm{Mu}$ named (rather confusingly) Moo who resided on the Yucatan before fleeing and seeking refuge on $\mathrm{Mu}$. Unfortunately for her she arrived in the mid-Atlantic shortly after Mu had subsided and travelled on to Egypt instead where she oversaw the construction of the Sphinx. In these accounts $\mathrm{Mu}$ is - for all intents and purposes - Atlantis by another name. But the lost continent soon took on a distinct identity of its own. This aspect began in the six volume Secret Doctrine written by theosophist Madame Blavatsky between 1888 and 1936, when Mu's name was incorporated into an entity entitled Lemuria that supposedly once occupied the oceanic space between Africa and Asia. The central syllable was subsequently extracted and stood alone again as the name of a third lost island civilisation, $\mathrm{Mu}$, located in the central and northern Pacific by Churchward (1926) and subsequently elaborated upon by Spence (1932) (who, confusing, referred to it as Lemuria again).

While Atlantis is not specifically referred to in The JAMs' and The KLF's output, it is present in the Illuminatus and provides visual and associative motifs that are deployed in the bands' singles and videos (albeit subsumed within the ensembles' primary references to $\mathrm{Mu} \mathrm{Mu}$ ). Wilson and Shea identify the Illuminati as originating in the lost island continent of Atlantis, the ruins of which lie on the Atlantic floor and include a pyramid with a single eye motif at its apex. The novels' heroes visit Atlantis in a submarine and glimpse its various grand buildings before returning to the surface. Elements of both Mu mytho-history and the

\footnotetext{
7 The trilogy was written as separate volumes in 1969-71 but was first published as a compendium in 1975 .

${ }^{8}$ See Young (1997) for details on cryptic references to The Illuminatus in The KLF and The JAMs' recordings and videos.
} 
representation of Atlantis in Shea and Wilson's trilogy appear in Cauty and Drummond's work with The JAMs and KLF, where they also intersect with the colourful intertwining of Atlantisian and Celtic studies pursued by Scottish writer Lewis Spence in the early $20^{\text {th }}$ Century. In a diverse body of work Spence both chronicled the supposed rites and beliefs of the Brythons (early Celtic inhabitants of the British Isles) in his 1905 volume Mysteries of Celtic Britain and went on to provide detailed accounts of the nature and demise of Atlantis in his 1924 volume The Problem of Atlantis. ${ }^{9}$ The latter volume concludes that fragments of Atlantisian civilisation survived the continent's inundation and took root in ancient Scotland. While the latter aspect of Atlantisian mytho-history is absent from any literary account besides Spence's, it provided a significant point of localisation for Cauty and Drummond's early 1990s' multimedia exploration of the aforementioned esoteric mythologies.

Complex as this body of mystic association is, the most significant aspect of Cauty and Drummond's deployment of this in their projects' mythology is that it was not rendered through 'concept albums' or through overarching mythical projects (such as 1970s' psychedelic band Gong's 'Radio Gnome Invisible' trilogy in $1973-74^{10}$ or more earnest French progressive rock band Magma's Kobaïan mythos ${ }^{11}$ ) but rather through a combination of brand assertion and slippery performances that have as much in common with Situationism as they do with music industry marketing. By "brand assertion", we refer to a tendency in popular music for bands to self-mythologise and to produce song, audio/visual and/or publicity material that primarily address the band's brand (rather than external subjects). Somewhat perversely (since branding suggests mainstream pop music of the type associated with the dull, conservative Illuminati in Wilson and Shea's trilogy), British punk rock ensemble The Clash represented a particularly intense embodiment of this approach. The group's early output, in particular, sought to distance it from mainstream rock by reiteration of its brand identity. This was manifest by the lyrics of early tracks such as 'Garage Band' (1977) or 'Complete Control' (1977) or, more overtly, in the titles and lyrics of songs such as 'Clash City Rockers' (1978), 'This is Radio Clash' (1981) and 'We are The Clash' (1982).

Cauty and Drummond's work engaged with a brand assertion approach in a dualistic way. A number of JAMs and KLF recordings feature frequent lyrical references to the JAMs with it being it unclear whether it is the fictitious Justified Ancients of $\mathrm{Mu} \mathrm{Mu}$ or the band (or both) that are the subject of the lyrics. This slippage combined with the duo's eschewal of explanations for their themes and oeuvre, constructed the ensembles(s) as engaging popular cultural performers (at least, for those with the proclivity to appreciate such esoteric populism). These aspects are condensed in The JAMs' regular logo (which also adorns various publicity material relating to The KLF). This directly appropriates the single eyed pyramid of Atlantis described in the Illuminatus, customised by its positioning at the centre of a 'ghetto-blaster' (portable music system) (Figure 1).

\footnotetext{
${ }^{9}$ Also see his aforementioned 1932 volume on Lemuria.

${ }^{10}$ Expounding a mythology of heroes, witches and "pot-head pixies" from Planet Gong, conceived by the band's founder, Daevid Allen, over the trilogy of albums Flying Teapot (1973), Angels' Egg (1973) and You (1974). For a detailed analysis of the band's representation of "drug utopias", see Briggs (2008).

${ }^{11}$ Magma was founded in 1969 by Christian Vander and has consistently explored a cosmological narrative concerning the inhabitants of the planet Kobaïa, with the ensemble's songs being written and sung in an invented Kobaïan language. See Holm-Hudson (2003) for a detailed discussion of this mythology.
} 


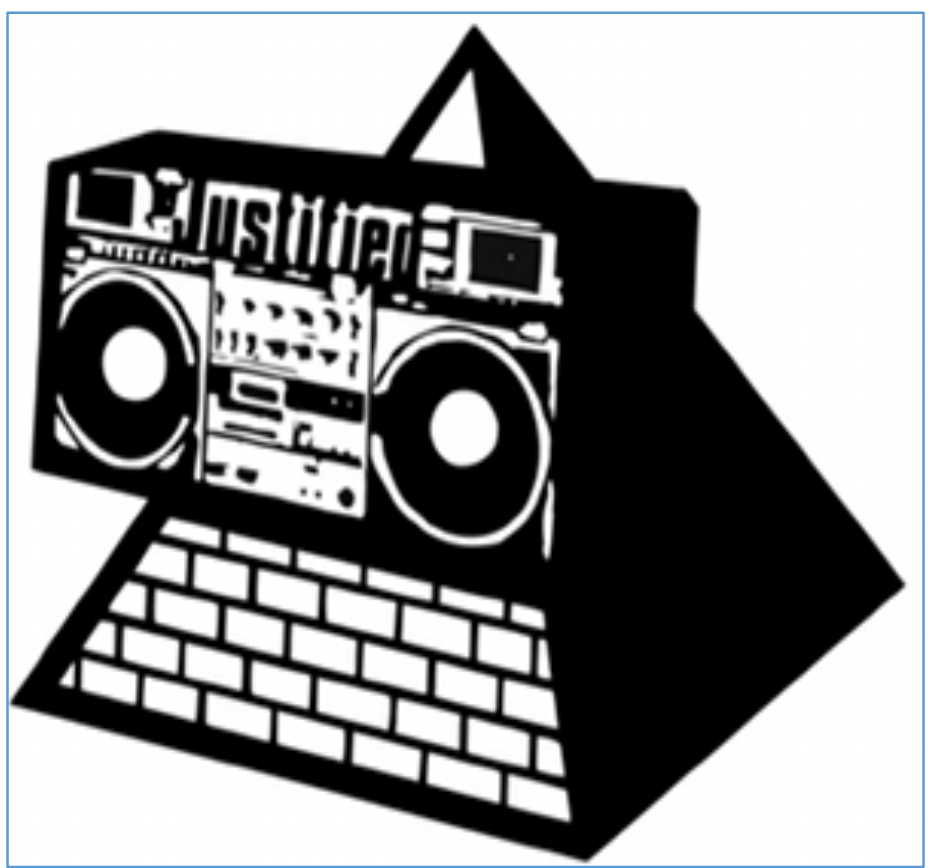

Figure 1 - KLF publicity image (1991) (note the prominent use of the word "Justified", directly aligning it with The JAMs)

Cauty and Drummond's over-arching tactics have been compared to those of the Situationists (see Higgs, 2012) and the audio/visual recordings of their work and archived communications have been conceived as comprising data that relates to - but only partially represents - the "spectacle" of their performance activities (ibid). This comparison merits discussion. The Situationists were a loose movement founded in the late 1950 os by a group of Western European artists, theorists and political radicals (see Stracey, 2014). The group rejected orthodox leftwing politics and political activities in favour of direct intervention into the symbolic order of advanced capitalism and rejected concepts such as individual authorship and copyright. One of their best known tactics was that of the détournement, which involved turning the logic of capitalism against itself in manners that illustrated its inadequacies. This approach manifested itself in various ways, such as re-utilising and/or altering public images by graffiti or staging disruptive performances in public spaces without announcement or explanation. ${ }^{12}$ Like Malcolm McLaren and other British punk provocateurs in the mid-late 1970s, Cauty and Drummond drew on this tradition by developing what might be termed 'promotional pranksterism' as a core activity - attracting

${ }^{12}$ In the case of Britain, one of the best know examples of the latter approach took place at Harrods, London's celebrated upmarket department store, in December 1967. A group of radical students dressed up in Father Christmas outfits and went into the toy department and started giving toys away to children as presents (thereby embodying the rhetorical 'spirit of Christmas'). Their action prompted security staff to intervene, scuffling with the Santas as they attempted to stop and detain them, causing stress and consternation amongst the parents and children present. 
attention to their oeuvre and commercial music releases through rhetoric, actions and events of the type discussed in the following sections.

\section{$\mathrm{Mu} /$ sic Videos}

Cauty and Drummond embodied the spirit of discord manifested in Shea and Wilson's trilogy and showed their affinity with the Situationists in their first recordings as The JAMs. These combined samples of popular music tracks used without copyright clearance with Drummond's heavily Scottish-accented vocal lines and Cauty's guitar and keyboard parts. While releases such as their debut single 'All you need is Love' attracted music press interest in the UK, their use of lengthy samples from ABBA's 1976 single 'Dancing Queen' in their track 'The Queen and I' (on their debut album 1987 What the Fuck is Going on? [1987]) prompted legal action that resulted in the album being withdrawn from sale. ${ }^{13}$ While further singles in this style (and a second album, Who Killed the JAMs?) followed in 1988, the duo also diversified into acid trance and ambient music styles with their first recordings as The KLF in 1988-1990. ${ }^{14}$ In 1991-1992 they achieved commercial success by reworking elements of their earlier oeuvre in their so-called "stadium house trilogy" of singles - "What Time is Love?', ' 3 a.m Eternal' and 'Last Train to Transcentral'. over electronic grooves and alternated a number of short musical and lyrical themes. The "stadium" aspect of their sound refers to the singles' dense sound mix, high dynamic range and the use of background crowd sounds to give the performances an epic quality (as if the artists were being cheered on by a massive crowd). They also featured frequent use of branding lyrics (such as "KLF is gonna rock ya" and "Ancients of Mu Mu"). Two further KLF singles followed the trilogy in 1992, a reworking of their album track 'Justified and Ancient', featuring US country star Tammy Wynette, and a remake of their debut single, featuring rock singer Glenn Hughes on lead vocals. ${ }^{16}$

While references to the Justified Ancients of $\mathrm{Mu} \mathrm{Mu}$ and to Mu itself were scattered through the duo's oeuvre prior to The KLF's stadium house trilogy, the trio of singles and their accompanying videos began more concerted explorations of the themes that became apparent in their later work. In this sense, Cauty and Drummond advanced their mythology in their early work in a similar manner to that of African-American electronic music duo Drexciya. The US duo released a series of recordings in the 199os that created a cryptic mythology that referred to the subsea realm of Drexciya (created/populated by the mutated progeny of African slaves thrown overboard alive into the Atlantic by European slave traders in the $18^{\text {th }}$ and $19^{\text {th }}$ centuries (see Gaskins, 2016). Eshun has characterised Drexciya's work as premised on "sonic fiction", a mode that he describes as the "convergence of the organisation of sound with a fictional system whose fragments gesture towards but fall short of the satisfaction of narrative" (2013: 138). ${ }^{17}$ In the case of Drexciya, he characterises this system as:

13 While formally withdrawn from circulation the track is currently online at: https://www.youtube.com/watch?v=DJUyqhj4zMM - accessed 16th August 2016.

${ }^{14}$ Examples of which are included on their 1990 album Chill Out.

${ }^{15}$ All of which were included on KLF's debut album The White Room.

${ }^{16}$ During this period the duo also reverted to The JAMs' moniker for another hit single, 'It's Grim Up North' (1991).

${ }^{17}$ We avoid using the term "sonic fiction" in our discussion of The JAMS and The KLF on the grounds that the term over-emphasises the sonic in favour of the band's aggregate of 


\section{Fitzgerald and Hayward: Chart Mythos}

assembled from track subtitles, the instructions in runout grooves, the statements on labels, the graphic images embedded within the support system of the record or $C D$ or the file, all of which feed into and reinforce each other to form a plane of consistency. Each of the elements in a sonic fiction can be extended across the discourse network of online culture. Indeed, the allusions, prompts and hints of the Drexciya mythos thrive in the hyperstitional engine of the internet. (ibid)

While Cauty and Drummond's evocations of $\mathrm{Mu}$ were essentially a fanciful form of mythological game-playing (rather than creative acts that expressed the deep-seated outrage of Drexciya's James Stinson and Gerald Donald at the atrocity of the African slave trade), the duo initially operated in an essentially similar manner to Drexciya, accruing mystique through obscurity and through creating aficionado networks that followed cryptic threads as they recurred in various contexts. With the commercial success of their 1991-92 singles Cauty and Drummond were able to gradually expand their invocations of the Justified Ancients and Mu beyond fragmentary sonic fictions and into songs supported by music video texts, CD sleeves, promotional artwork and films. In this manner, their address to $\mathrm{Mu}$-ian themes transitioned from the Drexciyan-esque approach of the duo's early JAMs phase through to the fully fledged audio-visual representations of their final music videos and Rites of $\mathrm{Mu}$ film.

The KLF's first hit single, 'What Time is Love?', differed from The JAMs' output (which featured sampled vocal sequences and Drummond's own vocals) by featuring a lead vocal from British Afro-Caribbean rapper Isaac Bello. The track has an epic feel, opening with the shouted exhortation from the MC5's (aforementioned) 'Kick out the Jams' single (ie "Kick out the Jams motherfuckers"). The sample cues the up-tempo dance-floor groove, followed by Bello's first rap sequence where he introduces the "crew" as The KLF, reiterates the song's title as its central question and cryptically refers to "the final chapter, prophetic, poetic". The track is heavily hook-laden, featuring a prominent vocable ("woo-woo') refrain performed by backing vocalists, a sampled female soul vocal hook ("I wanna see you sweat") and a main instrumental riff with semitone hook. In the accompanying video, the energy of the song's groove is highlighted by the sparks emanating from Cauty and Drummond's guitar and keyboards (respectively) and by the dancers' animated gestures. The video also includes a Mu-ian aspect by virtue of Bello, Cauty and Drummond being positioned on the lower tier of a pyramidal stage below dancers and extras lip-synching lyrics and simulating playing instruments (the pyramid being a symbol of Atlantis in the Illuminatus trilogy and one adopted by the band in their logo). While not directly connected with $\mathrm{Mu}$-ian imagery the video's representation of Bello performing while wearing a kufi (a traditional brimless, rounded African cap) and the presence of three black male dancers of Zulu-esque appearance, clutching hide-covered shields and spears alongside the other Caucasian performers, gives the (visually represented) ensemble a sense of jumbled exotic otherness. ${ }^{18}$

elements. In the remainder of the article we describe the approach more specifically as "Drexciyan".

${ }^{18}$ While the song does not give any context to the video's African-ist elements these are cryptically referred to in part of Ricardo de la Force's rap in the follow-up single ' 3 a.m. Eternal' (which alludes, in passing to "talking 'bout the Mu Mu - Justified Ancient Liberation Zulu"). 
The lyrics of the follow-up single, ' 3 A.M. Eternal', also frequently repeat the name "Ancients of $\mathrm{Mu} \mathrm{Mu"} \mathrm{in} \mathrm{rapper} \mathrm{Ricardo} \mathrm{de} \mathrm{la} \mathrm{Force's} \mathrm{vocal} \mathrm{part} \mathrm{(and} \mathrm{seemingly} \mathrm{answer} \mathrm{the} \mathrm{central}$ question of the preceding single with the answer that it's " 3 a.m. Eternal"). After an extended intro section featuring densely textured electronic sounds the song's main sequence is propelled by a heavy bass part and syncopated kick drums and features multiple vocal hooks, short melodic ideas, a series of rhythmic breakdowns and an exotic-sounding melody played on a Vietnamese kèn bầu (double reed oboe). The British music video ${ }^{19}$ combines $^{2}$ images of performers dressed in blue robes adorned with the KLF logo lip-synching and miming playing instruments behind Cauty and Drummond (on a similar pyramidal stage set up as the 'What Time is Love' video) with sequences that centre on de la Force declaring his rap onstage and from the back of a car, black female performers miming the song's title refrain and occasional shots of Cauty and Drummond in the Ford Galaxie police car that features in various KLF visual material from the period.

The video for 'Last Train to Transcentral' uses essentially the same stage set up as ' 3 A.M. Eternal' (although with Cauty apparently playing sitar and with different vocalists lipsynching particular sequences and refrains) intercut with blurry shots of a model train and of The KLF's Ford Galaxie car going through a futuristic cityscape and mountains. The lyrics commence by offering the statement that "This is what KLF is about" but ultimately fail to deliver anything more than an invitation to accompany the band on the "last train to Transcentral" (a destination that only the duo's closest aficionados would recognise as the nickname of the South London squat where they developed many of their ideas for the ensemble).

If the three stadium house singles and their accompanying videos did little more than extend the cryptic Drexciyanesque aspects of The JAMs' early releases into music video formats, the video for the ensemble's next release, 'Justified and Ancient,' realised aspects of Mu and The JAMs' mythology in a more concentrated context. 'Justified and Ancient' has a distinctly different feel from the preceding stadium house trilogy. After an opening with a 3-part female choral sequence announcing, "All bound for Mu Mu land" accompanied by synth strings, a retro funky shuffle groove with wah-wah guitar sounds ${ }^{20}$ kicks in. Wynette's vocal parts are also in marked contrast to the repeated vocal snippets used in the previous singles, appearing as a long, contoured, multi-phrase melody with frequent sustained notes. The lyrics describe the Justified Ancients as serious and determined but quickly undercut this by also describing that they drive an "ice cream van... with still no master plan." ${ }^{21}$ In the manner described earlier, many of the lyrics are direct (and reiterative) brand assertions, repeatedly name-checking the JAMs and $\mathrm{Mu} \mathrm{Mu} \mathrm{Land} \mathrm{and} \mathrm{also} \mathrm{inscribing} \mathrm{Wynette's}$ presence in the recording as a direct reverse of the $\mathrm{MC}_{5}$ 's previously mentioned support for the Illuminati (in 'Kick out the Jams') by reporting Wynette's willingness to respond to The

\footnotetext{
${ }^{19}$ Different videos were completed for the UK and US releases.

${ }^{20}$ As one of the anonymous referees for this article identified, the wah-wah guitar in the introduction to 'Justified and Ancient' references the introduction to Jimi Hendrix's 'Voodoo Chile Slight Return' (1970). The parallels with KLF crypto-mythology may be evident as Hendrix delivers the song's lyrics in the voice of a voodoo priest. In the lyrics he also intones: "Well, I stand up next to a mountain/Chop it down with the edge of my hand/Well, I pick up all the pieces/ And make an island".

${ }^{21}$ The lyrics also refer back to the ensemble's previous single (by commenting that "the last train left an hour ago", also bound for Mu Mu Land [suggesting the "Transcentral" referenced in the previous song's lyrics as Mu Mu Land").
} 
KLF's phone call and "Stand by The Jams". ${ }^{22}$ The song ends with the repeated chant of "Ancients of Mu Mu" and "All bound for Mu Mu land".

The music video is staged on a set that resembles a Mayan pyramid located next to an expanse of water where a small submarine has surfaced (inviting interpretation as the submarine that features, searching for Atlantis, in the Illuminatus trilogy). The stage features a large cast miming singing and instrument playing in a similar manner to the earlier "What time is love?" video and also includes performers dressed in Zulu-style attire and performing African dance moves. ${ }^{23}$ In the video, the two Justified Ancients (implicitly Cauty and Drummond ${ }^{24}$ ) are represented wearing hooded monks' robes with a single horn protruding from their foreheads (similar to the lead figure in Figure 2), an unusual image that recalls the minotaur of Minoan mythology but with a single protuberance. ${ }^{25}$ The final repeated lyrical refrains of "Ancients of Mumu" and "All bound for Mu Mu land" are mimed en masse by the cast as the wave the horned duo off. ${ }^{26}$

In a manner that precludes any characterisation of the duo's development of Mu-ian themes as a linear and/or focused activity, The KLF's final single - 'America: What time is love? reworked their original single (ie 'What time is love'?) by adding a substantial spoken introduction and sequences of lyrics that present the song and video as marking the thousandth anniversary of the Justified Ancients' accidental discovery of America. Fittingly, in this regard, the arrangement combines an incongruous batch of musical elements, including orchestral horns with a rising $5^{\text {th }}$ motif, wind sound effects, rock guitars mixed with electronic beats, a rap, high-set male rock vocals, a Russian-style (minor key) folk melody performed by a male chorus and Carl Orff-style rhythmic chanting. The song lyrics relate that whilst seeking Atlantis in the Atlantic Ocean the Justified Ancients "discovered" America and (somehow) "founded" the present-day nation of the USA (many centuries before the European colonisation that actually precipitated its founding). Opening with a narrator declaiming from a small rock in the sea, the black and white video represents the ocean crossing as occurring in a Viking-style long-boat and features an ensemble miming to the song on-deck. Passing the three ethereal maidens who appeared in the earlier 'What

\footnotetext{
${ }^{22}$ The line and its melody being an obvious reference to the title of Wynette's best known single, 'Stand by your Man' (1968).

${ }^{23}$ The performers include noted South African singer and dancer Doreen Thobekile and they appear to be performing broadly generic moves rather than elements of any specific indigenous African choreographic repertoire.

${ }^{24}$ It is unclear - and largely irrelevant - whether the performers are actually Cauty and Drummond.

${ }^{25}$ Higgs (2012) examines a number of synchronicities between the TV program $D r$. Who and Cauty and Drummond's work with The JAMs/KLF (exemplified by their production of the Doctorin' the Tardis single and music video) but does not refer to the representations of Atlantis in the TV series. While there is no evidence for these directly influencing the KLF's representations of the lost continents of Atlantis and $\mathrm{Mu}$, it is notable that an undersea Atlantis was the location for two series of the Sci-Fi program, a four-part story entitled The Underwater Menace (Julia Smith, 1967) and a six part one entitled The Time Monster (Paul Bernard, 1971), the latter of which includes a representation of the horned minotaur of Minoan mythology with the torso of a man and a bull's head.

${ }^{26}$ It's ambiguous as to off to where? While the lyrics suggest them departing for $\mathrm{Mu} \mathrm{Mu}$, Higgs offers a different interpretation, regarding the horned duo as being farewelled from it (2012: 184).
} 
time is love' video, who point them on their way, the boat finally reaches shore where it is shown in flames as a hoard of Viking-like Mu-ians swarm ashore. While absent from the single and music video soundmix, the extended 12" version of the song released by KLF Communications ends with crowd noises and a young American female voice innocently asking what might be termed the meta-question of The KLF's career, "Are those guys for real? I mean what's with all this Justified Ancients of Mu Mu shit?"

\section{The Rites of $\mathrm{Mu}$}

In 1991 The KLF issued invitations to a number of journalists and media industry figures to attend a summer solstice event entitled "The Rites of $\mathrm{Mu}^{27}$ on Friday 21st June in an undisclosed location. The invitation stated that "You'll be transported to the lost continent $\mathrm{Mu}$. Bring your passports". This specification was - as with many of the duo's oeuvre - telling in its ambiguity. It could both be interpreted as characterising $\mathrm{Mu}$ as an actual (ie physical) location capable of being travelled to (and further normalising that location as a contemporary political entity that required passports). It could also be read in the sense of it being the Rites of Mu that would offer the (spiritual-imaginative) transport to Mu. Those accepting the invitation were transported to the sparsely inhabited island of Jura, in the Inner Hebrides, off Scotland's central west coast. Jura was far from an incidental location. While not profiled in any of the band's lyrics or written statements it was a location of special importance to Cauty and Drummond (just as Transcentral was) since it had served as a retreat for them to consider the final phase of work with The KLF in 1990 (Higgs, 2012: 141-142). In this sense it served as an established sanctum, to which an elite group were invited to travel deeper into the duo's esoteric mysteries.

The necessity of providing passports to a waiting official (Drummond himself, in uniform), who duly examined and stamped them with The KLF's ghetto-blaster and eyeball logo, rendered the island less like a lost continental civilisation and more like an idiosyncratic, small island micro-nation. But while there are notable examples of these elsewhere in Scotland, ${ }^{28}$ it is more apt to compare the island (as represented to those arriving on it) as akin to Iona in the Inner Hebrides, which was an isolated bastion of Gaelic Christianity in the 6th-9th centuries. But unlike Iona, which sustained its autonomy and community of faith for many centuries, Cauty and Drummond's brief performance created a temporary space in which their mythos and logic systems briefly prevailed.

As it transpired, the visitors to the island became participants in events that were modelled on those that took place in another fictional location, Summerisle, the mysterious western Scottish island upon which the British cult horror film The Wicker Man (Robin Hardy, 1973) was set. The film represents an island ruled by an autocratic lord who leads a pagan religion and oversees the staging of a series of rituals designed to deliver bountiful harvests and thereby ensure the island's prosperity. Loosely inspired by the mystical Findhorn community on the Moray Firth ${ }^{29}$ and by David Pinner's 1967 novel 'Ritual', the island

\footnotetext{
${ }^{27}$ Note the specification of $\mathrm{Mu}$ (rather than $\mathrm{Mu} \mathrm{Mu}$ ), suggesting reference to the concept of Mu that pre-existed the Illiminatus, rather than the novels' particular characterisations of Mummu land.

${ }^{28}$ See, for example, Grydehøj (2014) and Hallerton and Leslie (2015) for discussions of fanciful Scottish island micronations.

${ }^{29}$ See Caddy (1967).
} 
portrayed on screen was assembled from a mixture of locations from across the south Western Highlands (including a number in Drummond's hometown of Newton Stewart). The film is notable for a dreamlike quality that turns nightmarish for Howie, the Scottish policeman (Edward Woodward), who finds his authority and Christian faith challenged at every turn. Folk-style songs and instrumental music play an important role in the film and, as we have identified in another context:

In its unsettling use of point of audition and music styles, The Wicker Man offers a subtly horrific scenario of destabilization and entrapment. Melodies unsettle and delude, lyrics convey double meanings and then the game's over... (Fitzgerald and Hayward, 2009: 109)

The final phrase of the quotation refers to the film's climax, when Howie is bound within a giant wicker man erected on a cliff top that is then immolated as the climax of a ritual accompanied by mass singing. Despite the horrific nature of such a death, the vivid image of the burning wicker man structure has established itself in contemporary popular culture, most notably via the burning of similar effigies as the climax of counter-cultural and/or music festivals. ${ }^{30}$

The KLF's event on Jura appears to have been a highly imaginative response to a series of questions by the press as to what their cryptic band mythology was about and what they hoped to achieve. In typical style, rather than delivering answers, the event further magnified the scope and scale of the band's mythological posturing created a colourful media story and formed the basis for KLF Communication's impressionistic documentary film of the event - The Rites of $M u$ (1991). Those arriving on the island were presented with a document to read which forms a significant part of the band's creative oeuvre. In particular, the document combines allusions to Biblical mythology with inventive embellishments that proffer the duo's perception of popular music practice as a primarily spontaneous and affective practice (rather than one that is readily explainable as a set of coherent intentions, actions and outcomes. The document expresses this clearly in its opening sentence:

Since that fateful day when man left by the Eastern Gate, fruit still fresh in his belly, those four beautiful handmaidens of Lucifer 'Why', 'What, 'Where' and 'When' have long tempted but never quenched his disastrous thirst for knowledge.

In contrast to the rhetorical four handmaidens' logocentric quest, The KLF invited their guests to participate in rites during which - somewhat improbably - "the fall of mankind will be reversed, returning him to the garden where the rest of creation waits" (presumably untroubled by the handmaidens). The document then shifts to identifying the duo as having felt assailed by requests for media interviews and commercial propositions and as having had their metaphorical "five minutes of fame" since their inception:

Since celebrating the Rites of Mu four seasons past, the KLF's moment has come: shimmering and dazzling like the haunting beauty of Aurora's race, it is

\footnotetext{
${ }^{30}$ See, for example The Wickerman Festival, held in Scotland since 2oo1. The now long running Burning Man festival was first held in Nevada in 1991, seemingly coincidentally, as its organisers were unfamiliar with the British film when they initiated the annual event and were not aware that the KLF were staging their performance in the same year.
} 
destined only to fade, While the moment lasts their Stadium House trilogy reverberates around the globe, the requests for live shows, interviews, TV appearances, remixes, promotional tours and commercial endorsements have spewed forth relentlessly from their fax machine.

The document goes on to identify that:

'Why', 'What', 'Where' and 'When' have been very busy; their seduction techniques near-perfect. The KLF, with regular feet of clay, have weakened at times and have pretended to answer the unanswerable. They too have tried to understand instead of accepting the unfocusable beautiful truth of the mystery that lies at the heart of pop's passing moments. (KLF Communications, 1991).

The duo's astute observations of the affective power and significance of popular music were a (typically cryptic) guide to what was expected of the invited guests, namely their participation in an event that was supposed to communicate affectively rather than to be decoded/interpreted as a coherent explanation of the group's project. The invited guests' main role in the event was to don yellow processional robes and chant as they followed Drummond (wearing the distinctive single-horned headpiece) over moors (Figure 2) to the site of a bonfire around a large wicker man figure with arms raised aloft. Upon the procession's arrival the four white-clad handmaidens arose from the sea, joined the participants, took their money from them and placed it inside the figure. The high priest then spoke an incantation in made up language (presumably meant to be $\mathrm{Mu}$-ian) before the effigy was burned. A party then followed.

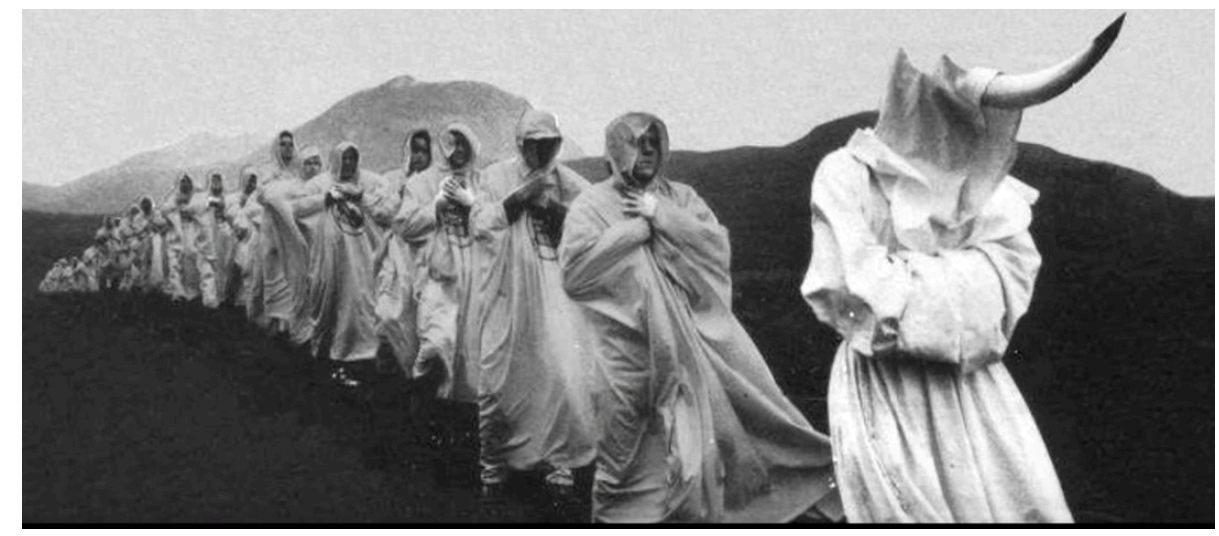

Figure 2 - procession image from The Rites of Mu

The event was followed by a coda, as the guests were transported to Liverpool for the Festival of Comedy. To their surprise, they were ushered on stage in hooded garb to sing an acapella rendition of 'Justified and Ancient' while Cauty and Drummond handed out ice creams from a van they had brought into the venue for that purpose. The dichotomy between the earnest, ritualistic nature of the Jura event and the impromptu rendition of the KLF song at a comedy festival is a classic Discordian strategy (Higgs, 2012: 28-35), immediately undercutting a gesture of one type with another so as to disorientate perception and require active interpretation. Despite this, the 29-minute film made to commemorate the solstice event is soberly narrated and has a ritualistic and dream/trance-like quality. In these regards it is 
similar to the "mythopoeic" mid-2oth Century avant garde films made by directors such as Maya Deren and Kenneth Anger. Discussing these, film critic P. Adams Sitney claimed that:

The triumph of the mythopoeic film in the early sixties sprang from the filmmakers' liberation from the repetition of traditional mythology and the enthusiasm with which they forged a cinematic form for the creation or revelation of new myths. (1974: 110)

Just as the "new myths" that the mid 2oth Century directors produced drew on established esoteric beliefs (such as Christian ritual and voodoo), Cauty and Drummond drew on the Illuminatus, The Wicker Man and Lewis Spence's writing to create their Western Isles' vision of a 'Brythonic' Mu.

In typical KLF fashion, the film exists in several versions, and was originally circulated in short episodes. The version discussed here is the 29 -minute long one currently available online. ${ }^{31}$ Paralleling the manner in which the Wicker Man soundtrack used a blend of music, spoken passages atmospheres and effects to help create an atmosphere of pagan ritualism, the Rites of $\mathrm{Mu}$ employs a range of evocative sound elements - including narration, drones, environmental and electronic sounds, almost-intelligible spoken words, vocal chants, and folk music style melodies - to enhance the strangeness of its mysterious island location.

After a short introductory sequence that displays the KLF's logo and represents them on a pyramid-shaped stage, the island is introduced via a montage of images, accompanied by brief sequences of vocal music and occasional processed sonic washes. The viewer is led through the central passage of the film by an earnest, close-to-mic narrator as those attending are seen arriving at the dockside border post, assembling and participating in the procession wearing ritual garbs stamped with the KLF logo. As the narrator declares "my mind empties of clutter and for the first time I am filled with clarity... and peace" a choir is heard on the soundtrack singing a minor key (Aeolian) folk-style melody with nonsense lyrics in an odd-sounding vocal timbre. The vocal passage continues, accompanying images of the KLF logo (created as a crop circle design) and images of a Viking longboat before three handmaidens appear, Lorelei-like, on a rock, gesturing off-screen, followed by a cut to The KLF's speaker stack adorned with a strip of silver foil. Subsequent sequences of the film combine repeated solo vocal and choral passages, heavily treated sound effects and vocal stabs. Choral sounds return for final images of the wicker figure against the sunset before the high priest in horned head piece is shown declaiming passionately in an invented language, engaging in a call and response with the crowd - as the screen scrolls through lines from the attendees' briefing document (shifting the context of this from instructions to the attendees to the viewer). The burning of the wicker man is accompanied by a children's choir, with added textures and musical effects. The burning sequence ends with the narrator intoning "The KLF may have brought us here but the Justified Ancients of Mu $\mathrm{Mu}$ have delivered us" before shifting to shots of the sea and shoreline as the soundtrack plays the final lines of children's choir before showing images of Cauty and Drummond relaxing on the shore and a final vocal refrain accompanied by fuzzed instrumental textures. $^{32}$

\footnotetext{
${ }^{31}$ See version uploaded at: https://www.youtube.com/watch?v=nRTGfxoz-nc - accessed $14^{\text {th }}$ August 2016.

${ }^{32}$ Thanks to Sarah and Seumas Mackinnon for their comments on the language use in choral sequences in the video.
} 
The film's narration is presented from the viewpoint of one of the invited guests who is initially bemused by the events unfolding before becoming immersed in and enraptured by them. ${ }^{33}$ In this manner, his reactions represent exactly what The KLF's introductory document asks of their guests. This is a convenient device to reinforce The KLF's stated vision for the event but also chimes with the reports of some of the journalists who attended. In this regard, Sarah Champion's lengthy report for $i-D$ magazine is more elaborate and dramatic testament to the affective power of participating in the event than the fictionalised participant-narrator's:

A colossal, concealed sound system calls us to worship. Tribal chanting and terrifying wailing is punctuated by more Mu Mantra. The King begins to chant, whipping up our emotions. Utterly hypnotised, we threw our hands in the air and answer with guttural mu-muing... the Wicker Man explodes into flames, fireworks sprinting through the sky like meteorites. Champagne bottles are broken open and the dancing starts. Only half an hour earlier, we had been cynical press officers, journalists and record company agents. Now, linked by a sense of awe... we are comrades in crime... Here is a delirious fantasy land.... Like Narnia, Alice's Wonderland or Lord of the Rings' Middle Earth, for a few fleeting hours The KLF create their own dream world, The Isle of Mu. (1991: 18)

As Champion's account characterises, the Rites of Mu enacted on Jura represented the point when the duo's fragmentary evocations of Mu coalesced into a performance event that briefly transported (at least some of) its participants to a mystic elsewhere, infused by the mythos of Mu. The duo moved from an early Drexciyanesque phase with The JAMs through the period of The KLF's chart success, where they coalesced aspects of Mu in their music videos before their economic success allowed them to invoke $\mathrm{Mu}$ in the physical realm through the events represented (and, thereby re-inflected and elaborated) in the Rites of Mu film. While singular in both the duo's oeuvre and popular music in general, the resignification of place by performance upon it is an enduring folkloric tradition in a number of cultures. With particular regard to islands, for instance, Suwa (2016) has identified the manner in which Sakurajima, an unremarkable rocky islet in Sai village in northern Japan, is annually transformed into the realm of the goddess Benzaiten as a result of a procession travelling to it, enacting rituals upon it and subsequently staging festivities to commemorate event (after which it reverts to its prior identity for the following 364 days).

The KLF's final live appearance, at the 1992 Brits (Music Industry) Awards night, marked their most extreme rejection of the music industry that they (like the Justified Ancients in the Illuminatus novels) had come to despise (at least after they achieved chart success...). Televised by the BBC, Cauty and Drummond's performance of ' 3 a.m. Eternal' with the grindcore ${ }^{34}$ band Extreme Noise Terror represented a chaotic, punk-like rejection of the music establishment, delivering a version of the song that dispensed with the subtler dynamics of its single release version in favour of a full-on thrash in which members of Extreme Noise Terror growled the chorus of "Ancients of $\mathrm{Mu} \mathrm{Mu}$ " in alternation with

\footnotetext{
33 The full text of the narration is posted online at: http://lunaticoutpost.com/archive/index.php?thread-47479o.html - accessed 12th August 2016

34 A particularly discordant and abrasive variety of metal, see Dee (2009: 53-72) for discussion.
} 
Drummond's rushed and garbled rendition of the verses. ${ }^{35}$ As the curtain went down an announcement sounded over the speakers, declaring "The KLF have now left the music industry". This was no mere hyperbole, with the KLF Communications label subsequently deleting all back catalogue and with the duo subsequently ceasing to record music or perform as either The JAMs or KLF. ${ }^{36}$ But while The KLF and The JAMs ceased recording, Cauty and Drummond had one more grand gesture up their sleeve. In 1994, two years after their exit from the music industry they quietly returned to Jura in the company of a journalist, Jim Reid, and their video maker, Gimpo. There, in a boathouse, in the middle of the night, in an eminently Discordian act, they methodically burned one million pounds in bank notes, representing a large slice of their profits from The KLF's music releases, in an act whose significance has continued to be debated (Brook, 1998, Higgs, 2014), adding another layer to their complex mythos.

\section{Conclusion}

Cauty and Drummond's work with The JAMs and The KLF engaged in intertextual appropriation and play with a number of musical, literary and audiovisual works to create increasingly successful commercial music releases. These (and the income they delivered) facilitated the duo's exploration of a number of cryptic themes that came to be a signature element of the ensembles' audiovisual output. In terms of this article's specific focus on the duo's invocation of Mu (and related mythic island entities), we have documented how the ensembles gradually aggregated a Drexciyanesque skein of elements "whose fragments gesture towards but fall short of the satisfaction of narrative" (Eshun, 2012: 138) that was more fully realised - and materialised - through the staging of the Rites of Mu on Jura and through the impressionistic documentation of the event in the eponymous film. While the duo's invocation of Mu on Jura was a singular rather than cyclic event, it followed a similar model to traditional practices of the type staged on Sakurajima (discussed above) in attempting to affect a transformation of sense of place for (and by) its participants that drew on a prior and more broadly dispersed mythology. The finality of the event in terms of Cauty and Drummond's work as The JAMs/KLF emphasises the manner in which the Rites involved the duo moving beyond a Drexciyanesque approach and towards a (one-off) localised performance practice. The rites, as performed, were both invented and derivative (with their modelling on aspects of The Wicker Man) and, thereby, invite comparison to folkloric rituals in general, which borrow, model or derive from related practices in an extended network of belief and performance in which originality is less significant than varieties of patterning that stand as markers of local difference. In these manners, while entirely fanciful and invented, Cauty and Drummond's work can be read as having more in common with aspects of folkloric tradition than might first appear, refiguring old tropes in new contexts through the performance of events that resonate in as complex ways as more traditional practices.

Thanks to Stuart Young, manager of The Library of Mu <http://www.libraryofmu.net>, for his informative feedback on an earlier draft of this article.

\footnotetext{
${ }^{35}$ Footage of the Brits performance is available online: https://www.youtube.com/watch?v=h_Iobo5zpJ4 - accessed 16th August 2016.

${ }^{6}$ See Young and Gilmore (1996) for details on Cauty and Drummond's musical collaborations subsequent to their retirement from the industry.
} 


\section{Fitzgerald and Hayward: Chart Mythos}

\section{BIBLIOGRAPHY}

Blavatsky, M (1888-1936) The Secret Doctrine, published as a single edition in 1999, Pasadena: Theosophical University

Briggs, J (2008) 'The Pot Head Pixies: Drug Utopias in the Music of Gong, 1968-1974, Social History of Drugs and Alcohol v23 n1: 6-23

Brook, C (1998) K Foundation burn a million quid, London: Ellipsis

Caddy, E (1967) God Spoke to Me, Findhorn: Findhorn Press

Champion, S (1991) 'The Rites of the KLF', $i-D$ July: 18-21

Churchward, J (1926) The Lost Continent of Mu, New York: Ives Washburn

Debord, G (1967) La société du spectacle - translated into English as The Society of the Spectacle and available online at:

https://www.marxists.org/reference/archive/debord/society.htm - accessed August 15h 2016)

Dee, L (2009) 'The Brutal Truth: Grindcore as the Extreme Realism of Heavy Metal', in Bayer, G (ed) Heavy Metal Music in Britain, London: Ashgate: 53-72

Drummond, B (2014) 'The five lessons I learned from Ken Campbell', The Guardian 18th November, online: https:/www.theguardian.com/stage/2014/nov/18/bill-drummond-fivelessons-i-learned-from-ken-campbell - accessed 18th August 2016

Ershun, K (2013) 'Aquatopia: The Imaginary of the Ocean Deep', in Farquharson, A and Clark, M (eds) Aquatopia: The Imaginary of the Ocean Deep, Nottingham and St Ives: Nottingham Contemporary and Tate St Ives: 138-149gett

Fitzgerald, J and Hayward, P (2009) 'Inflamed: Synthetic Folk Music and Paganism in the Island World of the Wicker Man' in Hayward, P (ed) Terror Tracks: Music, Sound and Horror Cinema, London: Equinox: 101-111

----- (2013) 'Rematerialisation: Musical Engagements with the British TV Series Doctor Who' in Donnelly, K and Hayward, P (eds) Music in Science Fiction Television: Tuned to the Future, New York: Routledge: 135-150

Gaskins, N (2016) 'Deep Sea Dwellers: Drexciya and the Third Space', Shima v1o n2: 68-8o

Gilbert, P (2014) ‘All very Wicker Man: Echo and the Bunnymen’s Ley Lines Tour, 1983', Mojo n267: 30

Grydehøj, A (2014) 'Captain Calamity's sovereign state of Forvik: Micronations and the failure of cultural nationalism', Shima v8 nı: 34-48

Hallerton, S and Leslie, N (2015) 'Islonia: Micronationality as an expression of livelihood issues', Shima v9 n2: 34-46 


\section{Fitzgerald and Hayward: Chart Mythos}

Hayward, P (2014) ‘Islands and Micronationality: An Introduction’, Shima v8 nı: 1-8

Higgs, J (2012) The KLF: Chaos, Magic and the band the Burned a Million Pounds, London: Phoenix

Holm-Hudson, K (2003) 'Apocalyptic Otherness: Black Music and Extraterrestrial Identity in the Music of Magma', Popular Music and Society v26 n4: 481-495

Jordan, P (2001) The Atlantis Syndrome, Stroud: Sutton Publishing

KLF Communications (1991) invitation to 'The Rites of Mu'

Lawrence, D and Messenger, P (1988) A Dream of Maya: Augustus and Alice Le Plongeon in Nineteenth Century Yucatan, Albuquerque: University of New Mexico Press

Pinner, D (1967) Ritual, London: Hutchison/Arrow

Shea, R and Wilson, R (1975) Illuminatus (trilogy), New York: Dell Publishing

Sitney, P.A (1974) Visionary Film - The American Avant Garde, New York: Oxford University Press

Spence, L (1905) The Mysteries of Britain: Secret Rites and Traditions of Ancient Britain Restored, London: Senate

----- (1924) The Problem of Atlantis, London: Rider

----- (1932) The Problem of Lemuria, London: Rider

Stracey, F (2014) Constructed Situations: A New History of the Situationist International, London: Pluto Press

Suwa, J (2016) 'Becoming Island: The Aquapelagic Assemblage of Benten-sai festivals in Sai Village in Northern Japan', paper presented at 13th annual International Small Island Cultures Conference, held in Naha, Okinawa, 17th - 19th June

Tolkien, J.R.R (1937) The Hobbit, London: George Allen and Unwin

----- (1954) The Lord of the Rings, London: George Allen and Unwin

Young, S (1997) 'The KLF and the Illuminatus' online: http://easyweb.easynet.co.uk/ stuey/klf/23.htm - accessed August 16th 2016

Young, S and Gilmore, N (1996) 'Transcentral - The KLF Mailing List - Frequently Asked Questions', online: http://music.hyperreal.org/library/publicity/klf/klf-faq.txt - accessed August 16th 2016 


\section{Fitzgerald and Hayward: Chart Mythos}

\section{DISCOGRAPHY}

The JAMs (1987) 'All you need is love' (white label 12" single release)

----- (1987) 1987 - What the Fuck Is going on? (album, The Sound of Music/ KLF Communications)

----- (1988) Who Killed The JAMs? (album, The Sound of Music/ KLF Communications)

----- (1991) 'It’s Grim up North’ (single, KLF Communications)

The KLF (1990) 'What time is love?' (single, KLF Communications)

----- (1990) Chill Out (album, KLF Communications)

----- (1991) '3 a.m. Eternal' (single, KLF Communications)

----- (1991) 'Last Train to Transcentral' (single, KLF Communications)

----- (1991) 'Justified and Ancient (Stand by The JAMs)' (with Tammy Wynette) (single, KLF Communications)

----- (1991) 'America: What time is love?' (single, KLF Communications)

The Time Lords (1991) ‘Doctorin' the Tardis' (single, KLF Communications)

\section{FILMOGRAPHY}

America: What time is love? (KLF music video, 1991, UK, KLF Communications)

Justified and Ancient (Stand by The JAMs) (with Tammy Wynette) (KLF music video, 1991, UK, KLF Communications)

Last Train to Transcentral (KLF music video, 1991, UK, KLF Communications)

The Rites of Mu (short documentary video, 1996, UK, K Communications)

The Wicker Man (feature film, 1973, UK, Robin Hardy)

3 a.m. Eternal (KLF music video, 1991, UK, KLF Communications)

What time is love? (KLF music video, 1990, UK, KLF Communications) 